\title{
PENENTUAN PRIORITAS PEMBANGUNAN INFRASTRUKTUR JALAN UNTUK MENGATASI WILAYAH KABUPATEN/KOTA DI PROVINSI JAWA TIMUR YANG MEMPUNYAI AKSESBILITAS RENDAH
}

\author{
Ir. Djoko Sulistiono, MT, Amalia Firdaus Mawardi, ST., MT dan Ir. Widjonarko, MSc (CS). \\ Departemen Teknik Infrastruktur Sipil, Fakultas Vokasi, Institut Teknologi Sepuluh Nopember \\ Email : djokosulis2016@yahoo.com
}

\begin{abstract}
ABSTRAK
Jaringan transportasi darat seperti jalan raya suatu wilayah mempunyai hubungan erat dengan kesejahteraan pada wilayah tersebut. Jaringan transportasi jalan yang baik diharapkan dapat memperbaiki aksesibilitas suatu wilayah, sehingga tingkat kesejahteraan menjadi ebih baik (PDRB tinggi). Demikian pula hal nya untuk wilayah Provinsi Jawa Timur yang mempunyai 30 kota / kabupaten dengan 43 ruas jalan nasional sepanjang $3038 \mathrm{Km}$, perlu diketahui tingkat aksesibilitas ke seluruh wilayah kota/kabupaten tersebut. Penelitian ini berusaha mengetahui wilayah yang mempunyai aksesibilitas tinggi dan aksesibilitas rendah. Prioritas jalan harus dilakukan pada wilayah kota/ kabupaten yang aksesibilitasnya rendah. Permasalahan wilayah mana yang mempunyai akasesbilitas yang tinggi dan aksesibilitas rendah Kemudian solusi apa yang harus dilakukan untuk wilayah kota/kabupaten yang aksesibilitasnya rendah Bagaiman model hubungan tingkat aksesibilitas dengan kesejahteraan wilayah (PDRB) Berapa besar Indeks Alpha Jaringan Jalan Tersebut.

Langkah awal yang dilakukan adalah mengumpulkan data primer dan atau sekunder (travel time), yang selanjutnya data waktu perjalanan antar wilayah (travel time) tersebut dicari lintasan terpendeknya menjadi matrix hubungan antar wilayah dengan sel matrix berupa waktu perjalanan terpendek (travel time) antar wilayah. Kemudian dengan indeks Shimbel dapat ditentukan wilayah yang mempunyai aksesbilitas tinggi dan aksesibilitas rendah. Penentuan prioritas pembangunan/ pemeliharaan jalan dalam upaya untuk perbaikan aksesibilitas dapat ditentukan dari tingkat aksesibilitas wilayah tersebut Selanjutnya dibuat hubungan Aksesibilitas dengan kesejatraan wilayah.

Hasil yang diperoleh melalui penelitian ini berupa infomasi wilayah kabupaten/kota di Jawa Timur yang mempunyai aksesibilitas tinggi seperti Mojokerto (total travel time 5879 menit) dan wilayah yang mempunyai aksesibilitas rendah seperti Banyuwangi (total travel time 14057 menit), sehingga dapat ditentukan prioritas pembangunan infrastruktur jalan dalam beberapa tahapan sesuai kemampuan anggaran yang tersediaa untuk perbaikan aksesbilitas wilayah Kota/ Kabupaten di Propinsi Jawa Timur. Model hubungan anatara tingkat aksesibilitas dengan tingkat kesejahteraan wilayah ditunjukkan dalam persamaan $Y=301539 x+2 E+08, R^{2}=0.1167 \quad$ artinya peranan infratruktur jalan dalam kesejahteraan wilayah sebesar $\quad 11,67 \%$, sisanya sebesar 88,33\% dipengaruhi oleh infrastruktur transportasi lainnya. Karena itu perlu dilakukan penelitian pengaruh infrastruktur transportasi lain bersama dengan infrastruktur jalan terhadap kesejahteraan wilayah (PDRB). Indeks Aksesibilitas/ mobilitas menunjukan angka masing2 sebesar 0,063>0,05 (syarat) dan 0,00007<0,005 (syarat), sedangkan Indeks Alpha Jaringan Jalan menunjukkan angka 0,26. Penambahan Jaringan Jalan akan menambah angka-angka tersebut atau kondisi jalan menjadi lebih baik
\end{abstract}

Kata Kunci : aksesbilitas, jaringan jalan, indeks shimbel, infrastruktur jala

\section{PENDAHULUAN}

\subsection{Latar Belakang}

Jawa Timur adalah sebuah propinsi di bagian timur Pulau Jawa, yang merupakan salah satu propinsi besar di Indonesia. Propinsi Jawa Timur mempunyai luas $47.922 \mathrm{~km} 2$, dengan jumlah penduduk 38.847.561 jiwa, dengan Surabaya sebagai lbukota nya. Kota Surabaya merupakan kota terbesar kedua setelah Ibukota Republik Indonesia, Jakarta (Adisasmita, 2011a). Jawa Timur merupakan propinsi yang memiliki luas wilayah terluas di Pulau Jawa. Jawa Timur memiliki panjang jalan 
nasional sebesar $3.038 \mathrm{~km}$, yang menghubungkan kota Surabaya sebagai ibu kota propinsi dengan 30 kabupaten dan 8 kotamadya lainnya (Adisasmita, 2011b). Hal ini berarti, Jawa Timur memiliki jaringan atau infrastruktur jalan terpanjang yang menghubungkan kota/kabupaten terbanyak di pulau Jawa .

Jawa Timur mempunyai wilayah yang menghasilkan PDRB kecil bila dibandingkan dengan wilayah lain, seperti Kabupaten Pacitan, Kabupaten Pamekasan. Keduanya menyumbang PDRB hanya sebesar 0,7\% dari keseluruhan PDRB Jawa Timur, dibandingkan dengan ibu kota Surabaya (24\%) dan Sidoarjo (8,5\%). Perbedaan besar ini diduga terkait adanya tingkat aksesibilitas jaringan infrastruktur jalan wilayah tersebut. Kota/ Kabupaten dengan aksesibilitas rendah perlu diperbaiki dengan menambah jaringan jalan baru pada beberapa tahapan sesuai kemampuan anggaran yang tersedia.

\subsection{Perumusan dan Pembatasan Masalah}

Dalam penelitian ini, permasalahan yang ditinjau adalah:

1. Manakah kabupaten/kota yang memiliki tingkat aksesibilitas tinggi/rendah,

2. Bagaimana hubungan besar PDRB dengan tingkat aksesibilitas suatu wilayah,

3. Bagaimana solusi untuk mengatasi kabupaten/kota yang memiliki tingkat aksesibilitas kecil.

4. Bagaimana menentukan prioritas pembangunan infrastruktur jalan pada wilayah yang mempunyai aksesbilitas rendah

Sedangkan batasan masalah yang diambil adalah penelitian ini adalah :

1. Penelitian dilakukan pada jaringan jalan arteri primer, dan beberapa jaringan jalan kolektor primer penghubung kabupaten/kota lokasi propinsi Jawa Timur,

2. PDRB yang dijadikan data merupakan nilai total tahun 2016 atas dasar harga berlaku (nominal),

3. Karakteristik utama sistem jaringan transportasi dalam penelitian ini menggunakan ukuran satuan waktu perjalanan (travel time).

\subsection{Tujuan}

Tujuan dari penelitian ini adalah :

1. Mengetahui urutan tingkat aksesibilitas kabupaten/kota di wilayah propinsi Jawa Timur.

2. Mengetahui hubungan tingkat aksesibilitas dengan besarnya PDRB yang dimiliki kota/kabupaten wilayah propinsi Jawa Timur.

3. Mengetahui solusi untuk kabupaten/kota yang memiliki tingkat aksesibilitas kecil sehingga dapat dijadikan dasar pembangunan jalan untuk perbaikan aksesbilitas.

4. Mengetahui prioritas pembangunan infrastruktur jalan pada wilayah yang mempunyai aksesbilitas rendah

\section{METODE PENELITIAN}

\subsection{Bagan Alir Penelitian}

Bagan alir dalam penelitian ini dimulai dari pengumpulan data, kemudian data tersebut dianalisa dengan menggunakan analisa jaringan, dan menghasilkan tingkat aksesbilitas, kemudian grafik hubungan aksesbilitas dan PDRB daerah sebagai indikator kesejahteraan wilayah. Untuk lebih jelasnya dapat ditunjukkan pada gambar 2.1 berikut : 


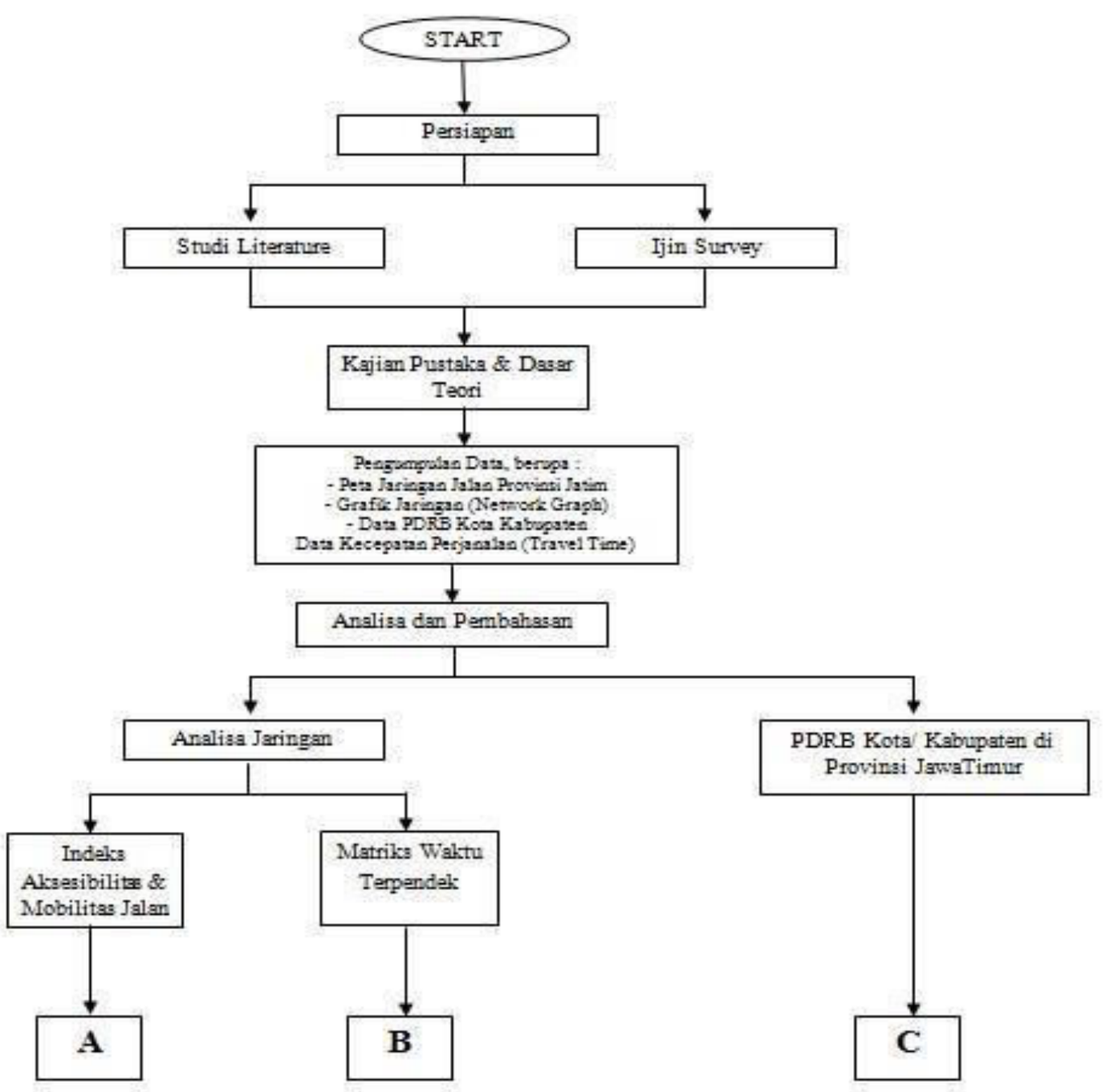

Gambar 2.1. Bagan Alir Metodologi Penelitian 


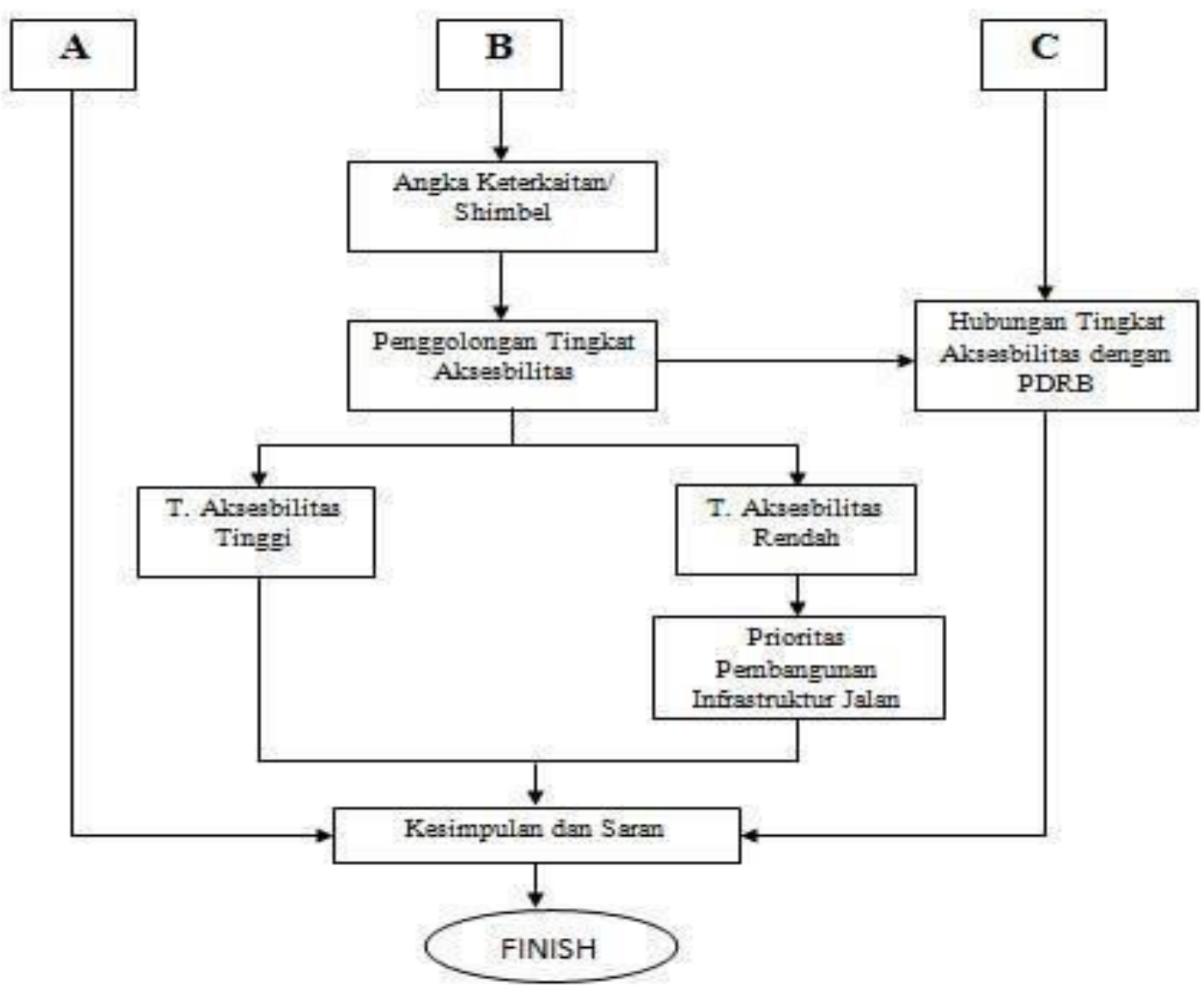

Gambar 2.1. Bagan Alir Metodologi Penelitian (lanjutan)

Indeks aksesibilitas dan indeks mobilitas digunakan menilai kinerja jaringan jalan (Hobbs, 1995). Kemudian Indeks Alpha digunakan untuk melengkapi penilaian kinerja jaringan jalan. Semakin besar indeks tersebut, maka kinerja jaringan jalan semakin baik (Morlok, 1978). Metode lintasan/ waktu terpendek digunakan untuk menentukan waktu terpendek antar kota/kabupaten. Melalui angka keterkaitan pada matrix waktu perjalanan antar Kota/ Kabupaten dapat dikelompokkan Kabupaten/ Kota yang mempunyai aksesbilitas tinggi ataupun rendah, sehingga dapat ditentukan prioritas pembangunannya (Djoko, Firdaus, \& Misbach, 2016). Selain itu, dapat dibuat hubungan antara kesejahteraan wilayah (PDRB) dengan tingkat aksesbilitas wilayah.

\section{HASIL PENELITIAN}

\subsection{Umum}

Penelitian ini merupakan penelitian dalam lingkup Laboratorium Transportasi dan Geoteknik Departemen Teknik Infrastruktur Sipil, karena itu melibatkan 3 (tiga) orang dosen tetap Departmen Teknik Infrastruktur Sipil Fakultas Vokasi ITS dan 1 (satu) orang mahasiswa Program Diploma IV 
Department Teknik Infrastruktur Sipil Fakultas Vokasi ITS yang mengambil Judul Tugas Akhir (TA) sejenis topik penelitian ini (Djoko, Firdaus, \& Asparini, 2015).

Data waktu perjalanan (travel time) antara Kota/ Kabupaten seluruh Jawa Timur telah berhasil didapat melalui aplikasi Google Map seperti terlihat pada Tabel. 1, selanjutnya. melalui angka keterkaitan data ini akan digunakan untuk menentukan wilayah Kota/ Kabupaten yang mempunyai aksesbilitas tinggi/ rendah. Kemudian untuk keperluan analisa jaringan digunakan Indeks aksesibilitas dan indeks mobilitas, selain Indeks Alpha dan telah didapat data jumlah Kota/ Kabupaten sebagai simpul (s) sebanyak 30 dan ruas $(r)$, jalan arteri antar Kota/ Kabupaten sebanyak 43 buah untuk wilayah Propinsi dengan jumlah penduduk.38.847.561 jiwa, luas wilayah $47.922 \mathrm{~km}^{2}$, panjang jalan nasional $3.038 \mathrm{~km}$.

\subsection{Hasil Penelitian dan Luaran yang Diperoleh}

Analisa jaringan dengan menggunakan matrix waktu perjalanan (travel time), telah didapat rata-rata waktu perjalanan antar Kota/ Kabupaten sebesar 7007 menit. Total waktu perjalanan dari suatu Kota/ Kabupaten ke Kota/Kabupaten lainnya dapat dilihat pada Tabel.1. Total waktu perjalanan tersebut bila lebih besar dari rata-rata waktu perjalanan, maka Kota/ Kabupaten tersebut mempunyai aksesbilitas rendah, demikian pula sebaliknya (Direktorat Jendral Binamarga Departemen PU, 1997).

Prioritas pembangunan jalan memperhatikan tingkat aksesbilitas tersebut dan diurutkan dari tingkat aksesibilitas paling rendah (travel time terbesar), hingga tingkat aksesibilitas paling tinggi (travel time terkecil) (Peraturan Pemerintah No.34 Tahun 2006 Tentang Jalan., 2006), sebagaimana diperlihatkan pada Tabel. 2 pada halaman berikut. 


\begin{tabular}{|c|c|c|c|c|c|c|c|c|c|c|c|c|c|c|c|c|c|c|c|c|c|c|c|c|c|c|c|c|c|c|c|}
\hline NODEVKABUPATEN & $\begin{array}{l}\frac{\pi}{12} \\
\frac{1}{6} \\
\frac{1}{3}\end{array}$ & $\begin{array}{l}\frac{8}{8} \\
\frac{1}{3} \\
\frac{8}{2}\end{array}$ & $\frac{8}{5}$ & $\begin{array}{l}\frac{1}{0} \\
\text { है } \\
\text { है }\end{array}$ & $\begin{array}{l}\frac{g}{\frac{g}{y}} \\
\frac{y}{\frac{0}{2}}\end{array}$ & $\begin{array}{l} \\
\frac{1}{2} \\
\frac{1}{2} \\
2\end{array}$ & $\begin{array}{l}8 \\
8 \\
8 \\
8 \\
8 \\
8\end{array}$ & 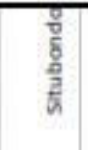 & $\begin{array}{l}8 \\
\frac{8}{3} \\
\frac{8}{3} \\
\frac{8}{2} \\
0\end{array}$ & 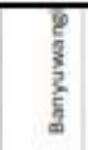 & 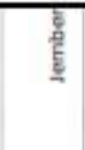 & $\begin{array}{l}\frac{9}{9} \\
\frac{9}{3} \\
\text { है } \\
3\end{array}$ & $\begin{array}{l}\frac{2}{2} \\
\frac{5}{2}\end{array}$ & $\frac{3}{8}$ & $\begin{array}{l}\frac{2}{2} \\
\frac{1}{2} \\
\frac{2}{3} \\
\end{array}$ & $\frac{1}{4}$ & 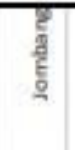 & $\begin{array}{l}\frac{2}{2} \\
\frac{1}{2} \\
\frac{2}{2}\end{array}$ & 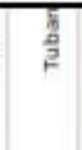 & 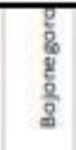 & $\frac{5}{\frac{3}{3}}$ & $\begin{array}{l}\frac{0}{0} \\
\frac{0}{2} \\
\frac{0}{6} \\
\frac{1}{2}\end{array}$ & $\frac{\pi}{\frac{\pi}{4}}$ & $\begin{array}{l}\frac{1}{8} \\
\frac{1}{8} \\
\frac{9}{2}\end{array}$ & $\begin{array}{l}5 \\
5 \\
0 \\
0\end{array}$ & 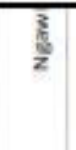 & 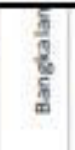 & $\begin{array}{l}\frac{2}{2} \\
\frac{d}{d} \\
\frac{1}{3}\end{array}$ & $\begin{array}{l}\frac{5}{1} \\
\frac{1}{8} \\
\frac{1}{2}\end{array}$ & 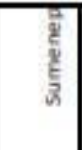 & $\begin{array}{c}\text { Total } \\
\text { Waltu } \\
\text { (s) }\end{array}$ \\
\hline Surabava & $\frac{0}{0}$ & $6 B$ & 49 & 90 & 100 & 141 & 200 & 348 & 309 & 477 & 351 & 259 & 197 & 288 & 282 & 230 & 157 & 221. & 171 & 198 & 349 & 359 & 343 & 323 & 408 & 337 & 60 & 102 & 184 & 290 & 7043 \\
\hline Sidoarjo & 58 & 0 & 108 & 130 & 73 & 84 & 144 & 299 & 313 & 423 & 302 & 204 & 129 & 249 & 243 & 173 & 119 & 188 & 203 & 224 & 274 & 324 & 303 & 292 & 433 & 299 & 114 & 212 & 230 & 300 & 0441 \\
\hline Gresik & 51 & 112 & 0 & 23 & 110 & 183 & 241 & 379 & 399 & 498 & 392 & 299 & 234 & 280 & $2 \pi$ & 230 & 159 & 214 & 129 & 159 & 293 & 337 & 312 & 319 & 447 & 204 & 110 & 210 & 224 & 290 & 7193 \\
\hline Lamongan & 88 & 130 & 51 & 0 & 82 & 187 & 239 & 374 & 393 & 490 & 379 & 299 & 234 & 242 & 231 & 107 & 110 & 171 & 88 & 102 & 250 & 295 & 278 & 272 & 403 & 212 & 140 & 249 & 202 & 330 & 6748 \\
\hline Mojokerto & 93 & 70 & 100 & 84 & 0 & 113 & 174 & 325 & 296 & 454 & 327 & 254 & 103 & 178 & 179 & 102 & 93 & 112 & 109 & 109 & 200 & 258 & 248 & 221 & 309 & 222 & 150 & 291 & 205 & 330 & 5879 \\
\hline Pasuruan & 134 & 82 & 178 & 200 & 128 & 0 & 30 & 211 & 230 & 340 & 217 & 138 & 104 & 241 & 270 & 210 & 105 & 230 & 277 & 289 & 319 & 303 & 347 & 339 & 400 & 335 & 198 & 285 & 300 & 369 & 7043 \\
\hline ProbolingBo & 191 & 143 & 238 & 251 & 180 & 58 & 0 & 139 & 170 & 294 & 170 & 91 & 130 & 284 & 332 & 273 & 222 & 278 & 332 & 334 & 372 & 414 & 398 & 373 & 520 & 390 & 231 & 347 & 349 & 400 & 7988 \\
\hline Situbondo & 324 & 207 & 350 & 359 & 314 & 207 & 154 & 0 & 00 & 147 & 114 & 195 & 293 & 405 & 448 & 377 & 333 & 399 & 427 & 434 & 483 & 522 & 508 & 473 & 028 & 303 & 352 & 440 & 445 & 305 & 10468 \\
\hline Bondowoso & 344 & 290 & 368 & 378 & 288 & 220 & 171 & 50 & 0 & 180 & 43 & 178 & 349 & 434 & 477 & 424 & 300 & 421 & 402. & 472 & 507 & 947 & 533 & 522 & 082 & 528 & 380 & 480 & 481 & 345 & 11138 \\
\hline Banyuwangi & 449 & 402. & 470 & 478 & 437 & 343 & 290 & 141 & 193 & 0 & 194 & 332 & 421 & 932 & 579 & 527 & 403 & 524 & 399 & 904 & 008 & 048 & 033 & 603 & 762 & 027 & 310 & 573 & 570 & 027 & $1 \mathrm{men}$ \\
\hline Jember & 351 & 299 & 370 & 389 & 330 & 234 & 182 & 100 & 42 & 187 & 0 & 144 & 320 & 392 & 439 & 453 & 399 & 419 & 457 & 400 & 904 & 351 & 529 & 474 & 040 & 525 & 383 & 477 & 477 & 539 & 11048 \\
\hline Lumajang & 244 & 189 & 278 & 292 & 201 & 149 & 100 & 200 & 187 & 318 & 139 & 0 & 209 & 332 & $3 \pi$ & 329 & 238 & 320 & 305 & 370 & 480 & 451 & 439 & 422 & 397 & 428 & 280 & 378 & 385 & 440 & 9180 \\
\hline Malang & 211 & 143 & 233 & 239 & 108 & 118 & 108 & 312 & 314 & 452 & 310 & 230 & 0 & 144 & 190 & 205 & 189 & 228 & 307 & 314 & 317 & 323 & 340 & 241 & 411 & 338 & 242 & 336 & 338 & 399 & $\pi 74$ \\
\hline Biltar & 209 & 245 & 272 & 248 & 189 & 239 & 284 & 414 & 424 & 940 & 387 & 340 & 139 & $a$ & 67 & 84 & 140 & 149 & 271 & 259 & 242 & 198 & 201 & 110 & 295 & 203 & 304 & 399 & 400 & 463 & 7905 \\
\hline Tulungagung & 201 & 239 & 248 & 231 & 178 & 284 & 335 & 400 & 474 & 984 & 432 & 384 & 191 & 63 & 0 & 94. & 130 & 119 & 254 & 225 & 190 & 141 & 200 & 98 & 228 & 235 & 293 & 390 & 391 & 474 & 7794 \\
\hline Kediri & 201 & 173 & 214 & 107 & 103 & 207 & 205 & 377 & 440 & 934 & 445 & 330 & 199 & so & 94 & 0 & 73 & OA & 202 & 173 & 100 & 191 & 195 & 112 & $2 \pi$ & 184 & 253 & 390 & 358 & 424 & 0805 \\
\hline Jambang & 140 & 117 & 143 & 116 & 53 & 154 & 210 & 350 & 379 & 478 & 350 & 205 & 182 & 100 & 123 & 69 & 0 & 64 & 139 & 153 & 159 & 207 & 193 & 174 & 325 & 179 & 190 & 280 & 300 & 367 & 6027 \\
\hline Ngarjuk & 199 & 184 & 213 & 177 & 110 & 219 & 273 & 410 & 434 & 527 & 509 & 309 & 220 & 144 & 112 & 03 & 05 & 0 & 180 & 111 & 90 & 144 & 123 & 102 & 257 & 111 & 244 & 341 & 340 & 407 & 6088 \\
\hline Tuban & 157 & 203 & 127 & 78 & 159 & 298 & 311 & 440 & 473 & 900 & 447 & 303 & 298 & 205 & 250 & 200 & 141 & 183 & 0 & $\pi$ & 243 & 288 & 247 & 305 & 397 & 199 & 208 & 300 & 314 & 377 & 7880 \\
\hline Bojonezoro & 199 & 228 & 150 & 100 & 173 & 273 & 320 & 448 & 300 & 579 & 403 & 377 & 320 & 249 & 221 & 174 & 100 & 110 & 79 & 0 & 100 & 210 & 108 & 200 & 322 & 110 & 238 & 336 & 339 & 398 & 7096 \\
\hline Madiun & 289 & 200 & 287 & 248 & 200 & 300 & 391 & 474 & 510 & 599 & 480 & 497 & 290 & 228 & 197 & 150 & 154 & 80 & 231 & 100 & 0 & 88 & 44 & 137 & 173 & 99 & 323 & 417 & 418 & 480 & 8078 \\
\hline Ponorogo & 329 & 312 & 332 & 297 & 251 & 342 & 399 & 513 & 552 & 039 & 539 & 452 & 311 & 194 & 142 & 180 & 211 & 140 & 280 & 212 & 53 & 0 & 67 & 82 & 117 & 103 & 300 & 400 & 401 & 519 & 8857 \\
\hline Magetan & 320 & 290 & 309 & 282 & 234 & 327 & 279 & 301 & 537 & 039 & 515 & 434 & 320 & 257 & 209 & 183 & 188 & 141 & 238 & 108 & 41 & 03 & a & 151 & 177 & 58 & 391 & 445 & 440 & 304 & 8019 \\
\hline Trenesalek & 307 & 289 & 308 & 275 & 124 & 330 & 372 & 490 & 513 & 020 & 471 & 427 & 233 & 112 & 99 & 102 & 178 & 163 & 303 & 271 & 140 & 118 & 150 & 0 & 170 & 189 & 350 & 448 & 453 & 314 & 8491 \\
\hline Pactan & 439 & 419 & 438 & 409 & 301 & 440 & 495 & 007 & 659 & 732 & 018 & 545 & 387 & 280 & 230 & 278 & 320 & 202 & 391 & 322 & 174 & 118 & 177 & 175 & 0 & 210 & 480 & 976 & 970 & 038 & 11700 \\
\hline Ngaw & 300 & 281 & 205 & 211 & 217 & 313 & 300 & 487 & 522 & 013 & 302 & 421 & 334 & 240 & 219 & 107 & 170 & 109 & 188 & 113 & 98 & 102 & 90 & 182 & 213 & 0 & 339 & 436 & 442 & 503 & 8397 \\
\hline Bangkalan & 90 & 112 & 104 & 149 & 220 & 183 & 242 & 373 & 403 & 497 & 379 & 289 & 229 & 314 & 305 & 271 & 190 & 258 & 218 & 240 & 352 & 391 & 375 & 309 & 512 & 362 & 0 & 210 & 134 & 202 & 7965 \\
\hline Sampane & 123 & 209 & 199 & 249 & 250 & 274 & 320 & 447 & 487 & 573 & 498 & 375 & 310 & 388 & 380 & 397 & 288 & 352 & 314 & 327 & 430 & 409 & 453 & 447 & 381 & 441 & 213 & 0 & 90 & 148 & 9948 \\
\hline Pamekasan & 179 & 219 & 212 & 259 & 201 & 2BS & 337 & 498 & 498 & 985 & 473 & 390 & 324 & 403 & 394 & 372 & 301 & 362 & 329 & 342 & 440 & 484 & 408 & 401 & 013 & 458 & 151 & 91 & 0 & 70 & 10227 \\
\hline Sumenep & 249 & 287 & 284 & 327 & 323 & 347 & 400 & 514 & 559 & 042 & 537 & 450 & 380 & 480 & 478 & 433 & 307 & 428 & 399 & 400 & 910 & 347 & 532 & 523 & 008 & 518 & 200 & 130 & 72 & 0 & 12020 \\
\hline Total Waktu (s) & 6549 & \begin{tabular}{|l|}
0270 \\
\end{tabular} & 6914 & \begin{tabular}{|l|l|}
6708 \\
\end{tabular} & \begin{tabular}{|l|l|}
5833 \\
\end{tabular} & \begin{tabular}{|l|l|}
6824 \\
\end{tabular} & 7088 & \begin{tabular}{|l|l|}
10074 \\
\end{tabular} & 11338 & \begin{tabular}{|l|l|}
14223 \\
\end{tabular} & \begin{tabular}{|l|l|}
10947 \\
\end{tabular} & \begin{tabular}{|l|}
9233 \\
\end{tabular} & \begin{tabular}{|l|l|}
7522 \\
\end{tabular} & \begin{tabular}{|l|l|}
7870 \\
\end{tabular} & \begin{tabular}{|l|l|}
7772 \\
\end{tabular} & \begin{tabular}{|l|l|}
6835 \\
\end{tabular} & \begin{tabular}{|l|l|}
6045 \\
\end{tabular} & \begin{tabular}{|l|}
6709 \\
\end{tabular} & \begin{tabular}{|l|l|}
7954 \\
\end{tabular} & 7042 & 8410 & 9123 & 8934 & 8590 & \begin{tabular}{|l|l|}
12057 \\
\end{tabular} & \begin{tabular}{|l|l|}
8093 \\
\end{tabular} & \begin{tabular}{|l|}
7093 \\
\end{tabular} & 10041 & \begin{tabular}{l|l|}
10070 \\
\end{tabular} & 11824 & \\
\hline
\end{tabular}


Tabel 2. Kota/ Kabupaten dengan aksesbilitas rendah dan tinggi di Provinsi Jawa Timur

\begin{tabular}{|c|c|c|c|c|}
\hline No. & Kota/ Kabupaten & PDRB & $\begin{array}{l}\text { Travel Time } \\
\text { (menit) }\end{array}$ & Tingkat Aksesbilitas \\
\hline 1 & Banyuwangi & $60,179,292.90$ & 1 & rendah \\
\hline 2 & Pacitan & $11,590,629.69$ & 1 & rendah \\
\hline 3 & Sumenep & $26,998,001.00$ & 1 & rendah \\
\hline 4 & Bondowoso & $14,484,920.90$ & 1 & rendah \\
\hline 5 & Jember & $56,376,970.00$ & 1 & rendah \\
\hline 6 & Situbondo & $14,795,800.00$ & 1 & rendah \\
\hline 7 & Pamekasan & $12,227,754.24$ & 1 & rendah \\
\hline 8 & Sampang & $14,697,297.30$ & 1 & rendah \\
\hline 9 & Lumajang & $24,456,796.75$ & 9 & rendah \\
\hline 10 & Ponorogo & $14,912,841.58$ & 9 & rendah \\
\hline 11 & Magetan & $13,875,867.13$ & 8 & rendah \\
\hline 12 & Ngawi & $14,990,354.50$ & 8 & rendah \\
\hline 13 & Trenggalek & $13,684,991.90$ & 8 & rendah \\
\hline 14 & Madiun & $13,874,666.14$ & 8 & rendah \\
\hline 15 & Tuban & $48,203,562.29$ & 7 & rendah \\
\hline 16 & Blitar & $26,790,303.30$ & 7 & rendah \\
\hline 17 & Tulungagung & $22,326,624.63$ & 7 & rendah \\
\hline 18 & Bangkalan & $14,517,326.10$ & 7 & rendah \\
\hline 19 & Probolinggo & $25,678,111.54$ & 7 & rendah \\
\hline 20 & Bojonegoro & $46,649,168.20$ & 7 & rendah \\
\hline 21 & Malang & $65,972,620.00$ & 7 & rendah \\
\hline 22 & Gresik & $100,748,593.90$ & 6 & tinggi \\
\hline 23 & Kediri & $30,438,992.89$ & 6 & tinggi \\
\hline 24 & Pasuruan & $5,949,432.40$ & 6 & tinggi \\
\hline 25 & Lamongan & $28,831,321.90$ & 6 & tinggi \\
\hline 26 & Nganjuk & $19,124,890.21$ & 6 & tinggi \\
\hline 27 & Surabaya & $406,196,760.30$ & 6 & tinggi \\
\hline 28 & Sidoarjo & $146,372,323.40$ & 6 & tinggi \\
\hline 29 & Jombang & $26,339,100.00$ & 6 & tinggi \\
\hline 30 & Mojokerto & $58,819,912.81$ & 5 & tinggi \\
\hline
\end{tabular}

Sumber : Hasil Analisa (2017)

Aksesibilitas rendah terdapat pada $30 \mathrm{Kota} /$ Kabupaten di Jawa Timur, sisanya 9 kabupaten/kota memiliki aksesibilitas tinggi. Prioritas pembangunan atau pemeliharaan jalan berdasarkan urutan Tabel. 2 diatas, untuk memperbaiki aksesibilitasnya.

Indeks Aksesibilitas yang merupakan pembagian panjang jalan ( $3.038 \mathrm{~km})$ dengan luas wilayah (47.922 $\mathrm{km}^{2}$ ) diperoleh 0,063 > 0,05 (syarat). Indeks Mobilitas yang merupakan pembagian panjang jalan $(3.038 \mathrm{~km})$ dengan jumlah penduduk (38.847.561 jiwa) diperoleh 0,00007 < 0,005 (syarat). Nilai indeks aksesibilitas dan indeks mobilitas menjadi semakin besar/baik bila jalan propinsi dan jalan kabupaten dimasukan dalam analisa. 
Indeks Alpha jaringan jalan nasional/ provinsi wilayah Provinsi Jawa Timur yang menghubungkan Kota/ Kabupaten di wilayah Provinsi Jawa Timur dirumuskan sebagai berikut Indeks Alpha $=\frac{r-s+1}{2 s-5}$ dimana s adalah jumlah kota/ kabupaten sebesar 30 dan $r$ adalah jumlah ruas sebesar 43 . Sehingga Indeks Alpha $=\frac{43-30+1}{2(30)-5}=\frac{14}{55}=0.26$

Semakin banyak ruas jalan ( $r$ ), maka kinerja jaringan semakin baik. Penambahan ruas jalan dalam upaya peningkatan aksesbilitas dapat memperbarui kinerja jaringan atau Indeks Alpha semakin besar.

Hubungan aksesibilitas dengan tingkat kesejahteraan suatu wilayah (PDRB) diperlihatkan pada Gambar dengan persamaan sebagai berikut $Y=301539 x+2 E+08$ dengan $R^{2}=s 0.1167$

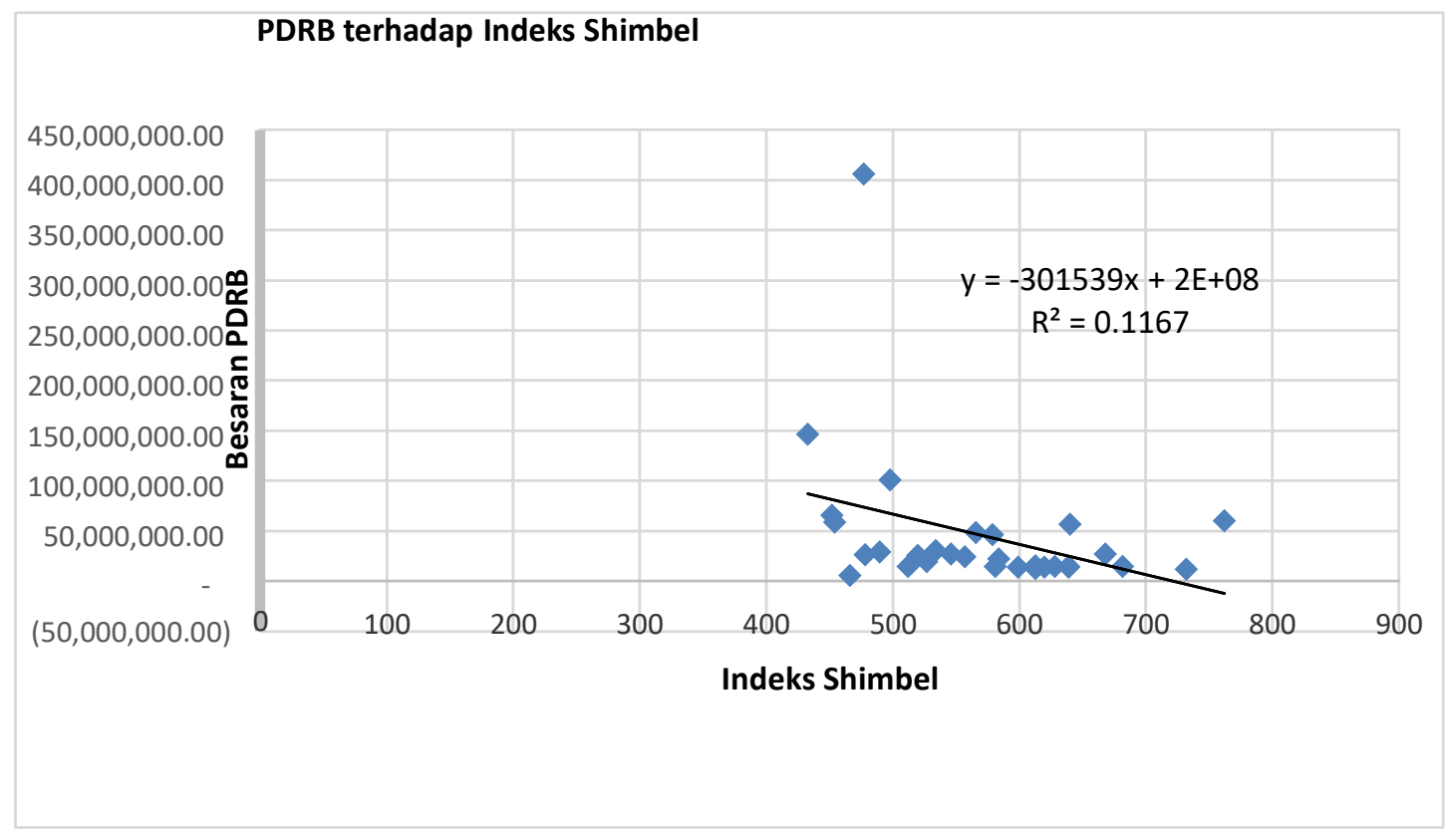

Gambar 3.1. Hubungan Antara Kesejahteraan Wilayah(PDRB) dengan Aksesibilitas (Indeks Shimbel)

Nilai $R^{2}=0.1167$ menunjukkan bahwa peranan jaringan jalan terhadap kesejahteraan wilayah sebesar $11,67 \%$ jadi ada faktor lain sebesar $88,33 \%$ yang mempengaruhi kesejahteraan suatu wilayah seperti jaringan jalan kereta api, jaringan tranportasi air, jaringan transportasi udara, sumber daya alam/ manusia dan kepemimpinan yang baik (Abubakar, 1995). Hal ini terlihat pada Kabupaten Banyuwangi, walaupun aksesibilitas melalui jalan raya paling jelek, tetapi mempunyai PDRB relatip lebih tinggi dari beberapa kota/kabupaten yang lain.

Kendala dijumpai adalah kesempatan untuk mengikuti Konferensi/ Seminar Nasional sesuai target luaran sampai akhir 2017. Kendala ini bisa diatasi dengan selalu mencari informasi tentang penyelenggaraan Seminar Nasional. 


\section{KESIMPULAN}

Sesuai hasil pembahasan, maka dapat disimpulkan hal-hal sebagai berikut :

1. Jawa Timur mempunyai 30 Kota/ Kabupaten yang aksesibilitasnya rendah dan 9 Kota/ Kabupaten dengan aksesbilitas tinggi.

2. Kota/ Kabupaten yang mempunyai aksesbilitas paling rendah adalah Kabupaten Ban yuwangi dengan total travel time ke Kota/ Kabupaten lain sebesar 14.225 menit.

3. Kota/ Kabupaten yang mempunyai aksesbilitas paling tinggi adalah Kota Mojokerto dengan total travel time ke Kota/ Kabupaten lain sebesar 5.833 menit.

4. Kota/ Kabupaten yang mempunyai aksesbilitas rendah harus diperbaiki dengan pembangunan jalan baru dan merawat jalan yang sudah ada (Singgih, Sulistiono, \& Asparini, 2015).

5. Indeks Aksesibilitas jaringan jalan di Propinsi Jawa Timur sebesar $=0,063>0,05$ (syarat), sedang. Indeks Mobilitas sebesar 0,00007 < 0,005 (Syarat). Indeks aksesibilitas dan mobilitas bisa bertambah bila ruas jalan propinsi dan kabupaten dimasukkan dalam analisa.

6. Kinerja jaringan dapat diketahui dengan Indeks Alpha sebesar 0.26. Penambahan ruas dalam rangka peningkatan aksesbilitas akan memperbesar Indeks Alpha atau kinerja jaringan menjadi semakin baik.

7. Hubungan aksesibilitas dengan kesejahteraan wilayah (PDRB) ditunjukkan dalam persamaan $\mathrm{Y}=301539 \mathrm{x}+2 \mathrm{E}+08$ dengan $\mathrm{R}^{2}=0.1167 \quad$ Hubungan dengan $\mathrm{R}^{2}$ sebesar 0.1167 menunjukkan peranan trasportasi darat (jalan raya) adalah sebasar $11,67 \%$ dan sisanya 88,33 \% kesejahteraan wilayah dipengaruhi moda transportasi lain (air, udara), sumber daya alam/manusia, kepemimpinan yang baik.

8. Peranan Infrastruktur Jalan terhadap Kesejahteraan wilayah sebesar 11,67 \%, menimbulkan keinginan meneliti Pengaruh Infrastruktur yang lain seperti Jalan Kereta Api, Bandara, Pelabuhan, secara bersama dengan Infrastruktur Jalan.

\section{DAFTAR PUSTAKA}

Abubakar, I. (1995). Menuju Lalu Lintas dan Angkutan Jalan yang Tertib. Jakarta: Direktorat Jendral Perhubungan Darat Departemen Perhubungan RI.

Adisasmita, S. A. (2011a). Jaringan Transportasi. Yogyakarta: Graha Ilmu.

Adisasmita, S. A. (2011b). Jaringan Transportasi dan Pengembangan Wilayah. Yogayakarta: Graha Ilmu.

Direktorat Jendral Binamarga Departemen PU. (1997). Tata Cara Perencanaan Geometrik Jalan Antar Kota. Jakarta.

Djoko, S., Firdaus, A., \& Asparini, A. (2015). Penggunaan Angka Keterkaitan untuk Penentuan Tingkat Aksesbilitas Kota/ Kabupaten di Wilayah Propinsi Kalimantan Barat. Jurnal Aplikasi Teknik Sipil, 13(1).

Djoko, S., Firdaus, A., \& Misbach, M. (2016). Penggunaan Angka Keterkaitan untuk Penentuan Tingkat Aksesbilitas Kota dan Kabupaten di Wilayah Propinsi Jawa Timur. Institut Teknologi Sepuluh Nopember.

Hobbs, F. (1995). Perencanaan dan Teknik Lalu Lintas. Yogyakarta: Gadjah Mada University Press.

Morlok, E. (1978). Introduction Transportation Engineering and Planning. New York, USA.: Mc Graw Hill Inc.

Peraturan Pemerintah No.34 Tahun 2006 Tentang Jalan. (2006). Indonesia. 
Singgih, P., Sulistiono, D., \& Asparini, A. (2015). Penyusunan Master Plan Sistem Jaringan Jalan di Kabupaten Mahakam Ulu, Kalimantan Timur. In Seminar Nasional Aplikasi Teknologi Prasarana Wolayah (ATPW) 2015.

Peraturan Pemerintah No.34 Tahun 2006 Tentang Jalan.

Undang-Undang Republik Indonesia No.38 Tahun 2004 Tentang Jalan. 